\title{
Médiévales
}

Langues, Textes, Histoire

48 | printemps 2005

Princes et princesses à la fin du Moyen Âge

\section{Sebastià Giralt i Soler, Arnau de Vilanova en la impremta renaixentista}

Manresa, Publicacions de l'Arxiu Històric de Ciències de la Salut (PAHCS), 2002, 218 p., tables, appendices, notes et bibliographie.

\section{Nicolas Weill-Parot}

\section{(2) OpenEdition}

\section{Journals}

Édition électronique

URL : https://journals.openedition.org/medievales/1088

DOI : $10.4000 /$ medievales. 1088

ISSN : 1777-5892

Éditeur

Presses universitaires de Vincennes

\section{Édition imprimée}

Date de publication : 1 juin 2005

Pagination : 168-170

ISBN : 2-84292-169-0

ISSN : 0751-2708

Référence électronique

Nicolas Weill-Parot, «Sebastià Giralt i Soler, Arnau de Vilanova en la impremta renaixentista », Médiévales

[En ligne], 48 I printemps 2005, mis en ligne le 02 décembre 2005, consulté le 24 avril 2022. URL :

http://journals.openedition.org/medievales/1088; DOI : https://doi.org/10.4000/medievales.1088

Ce document a été généré automatiquement le 24 avril 2022

Tous droits réservés 


\section{Sebastià Giralt i Soler, Arnau de Vilanova en la impremta renaixentista}

Manresa, Publicacions de l'Arxiu Històric de Ciències de la Salut (PAHCS), 2002, 218 p., tables, appendices, notes et bibliographie.

\section{Nicolas Weill-Parot}

1 L'image de l'un des plus célèbres médecins du Moyen Âge, Arnaud de Villeneuve (v. 1240-1311) a été graduellement obscurcie par les épaisseurs d'apocryphes, de légendes et de malentendus, qui l'ont recouverte au fil des siècles. La recherche historique et philologique, sous l'impulsion en particulier des travaux de Juan Antonio Paniagua et grâce aussi à l'entreprise d'édition critique des Opera medica omnia conduite sous la direction de ce dernier, du regretté Luís García-Ballester et de Michael McVaugh, fait émerger progressivement la figure véritable du médecin catalan. C'est dans ce mouvement de renouveau scientifique que s'inscrit le travail de Sebastià Giralt i Soler sur les éditions de la Renaissance de l'œuvre médicale du grand maître. Ces premières éditions imprimées ont en effet puissamment contribué au processus de déformation de son image - processus qui avait été entamé dès le XIV siècle.

2 S. Giralt i Soler étudie d'abord les éditions des œuvres particulières. Conservées dans un grand nombre de copies manuscrites, certaines d'entre elles connaissent les honneurs des presses, en particulier dans la période 1480-1520. Ces impressions contribuent à brouiller davantage l'image du médecin: d'une part à cause de l'effet démultiplicateur qu'elles induisent, d'autre part à travers la création de fausses attributions dont elles se rendent coupables; ce fut le sort du commentaire au Regimen sanitatis Salernitanum, rédigé sans doute par un maître de Louvain, sous prétexte qu'il fut édité à Louvain dans les années 1480 conjointement au Regimen sanitatis ad regem Aragonum d'Arnaud de Villeneuve.

3 S. Giralt i Soler divise les éditions générales en deux grands blocs chonologiques: d'abord, les éditions en lettres gothiques de la première moitié du $\mathrm{xvI}^{\mathrm{e}}$ siècle, imprimées à Lyon $(1504,1509,1520,1532)$ ou à Venise $(1505,1527)$ (en ajoutant celle, inachevée, de Strasbourg 1541); ensuite, les éditions en lettres romaines de Bâle 1585 et de Lyon 1586. 
4 L'édition princeps de Lyon 1504, réalisée par les soins du médecin génois Tommaso Murchi, servit de texte de base aux éditions postérieures. Pour les œuvres déjà éditées, il ne semble pas que d'autres manuscrits aient été de nouveau consultés contrairement à ce qu'indiquent souvent les préfaces. Toutes ces éditions étaient destinées à des médecins, à des étudiants en médecine, mais aussi à des lecteurs qui étaient férus de philosophie naturelle ou qui s'intéressaient à la préservation de la santé. Tout au long de son étude, S. Giralt i Soler est attentif à la question des traductions en vernaculaire. Après le premier tiers du XVII ${ }^{\mathrm{e}}$ siècle l'amenuisement de l'intérêt pour les œuvres arnaldiennes se décèle à la fois dans la diminution très nette du nombre d'écrits édités et dans la destination des quelques réimpressions à un public manifestement profane.

5 Les éditions des œuvres arnaldiennes firent l'objet de l'attention des autorités inquisitoriales. De fait, si, pour reprendre l'expression de J. A. Paniagua, la médecine arnaldienne avait été le " paradigme de la médecine scolastique ", ses écrits spirituels, en revanche, lui avaient valu de son vivant bien des déboires. C'est bien au nom de cette condamnation médiévale de ces seuls écrits spirituels que l'ensemble de son œuvre - spirituelle ou non - se trouva mise à l'index en 1559. Mais dans l'index de 1564 le nom d'Arnaud n'apparaissait plus et, du reste, il était désormais admis que les œuvres non théologiques d'hérétiques pouvaient échapper à la condamnation qui frappait leurs auteurs. En revanche, l'inquisition espagnole censura dès 1584, et de façon réitérée jusqu'en 1707, un certain nombre d'œuvres arnaldiennes ou pseudoarnaldiennes sur les sciences occultes: oniromancie, astrologie, magie talismanique et alchimie. La plupart des exemplaires des Opera d'Arnaud de Villeneuve conservés dans les bibliothèques d'État espagnoles portent la trace de cette censure inquisitoriale.

6 S. Giralt i Soler parvient à mettre en relation la chronologie des éditions des Opera d'Arnaud avec les grandes évolutions du contexte intellectuel et scientifique. Ainsi, l'éclipse entre la période des éditions gothiques et l'édition de Bâle de 1585 s'expliquerait par la victoire de l'hellénisme médical qui aurait inévitablement marginalisé une œuvre aussi marquée par la tradition galénique arabo-latine. Quant à l'édition de Bâle elle-même, elle s'expliquerait par un nouveau contexte: Bâle était devenu l'un des centres majeurs de l'édition des textes portant les empreintes du néoplatonisme, de l'hermétisme et de la kabbale, ainsi que celles de l'alchimie et du paracelsime. Ces deux derniers centres d'intérêt surtout auraient guidé l'entreprise de l'éditeur Conrad Waldkirch. Cet engouement pour Arnaud n'était donc pas dépourvu de paradoxe, puisque l'œuvre alchimique du médecin catalan est très probablement entièrement apocryphe et que, par ailleurs, il s'était voulu le représentant par excellence $\mathrm{du}$ galénisme (courant contre lequel s'escrimaient au contraire très largement les paracelsiens). Mais, en réalité, c'est aussi, et plus souvent encore, la médecine pratique que l'on valorisa alors dans le corpus arnaldien.

7 Le succès renaissant d'Arnaud est donc complexe et ambivalent: on le voit tantôt comme un auteur maniant les langues chères à l'humanisme, s'occupant de disciplines les plus diverses, connaissant en particulier les procédés occultes de la nature. Le monde protestant s'intéressa, lui aussi, à ses écrits spirituels. C'est cette image contrastée, faussée et complexe que Sebastià Giralt i Soler s'efforce de clarifier et de cerner à travers un examen exemplaire de ces éditions générales ou particulières de l'œuvre médicale arnaldienne. Ce faisant, il donne aux études arnaldiennes, dans un appendice de 80 pages, un instrument de travail indispensable: liste des œuvres imprimées et des éditions, tableaux statistiques, éditions des dédicaces et préfaces des 
différentes éditions et celle de l'Arnaldi Vita de Symphorien Champier. L'ouvrage fournit ainsi des clefs pour comprendre le passage des manuscrits médiévaux à l'impression renaissante et le destin contrasté des auteurs médiévaux à l'époque de l'humanisme, de la Réforme et de la Contre-Réforme. 